
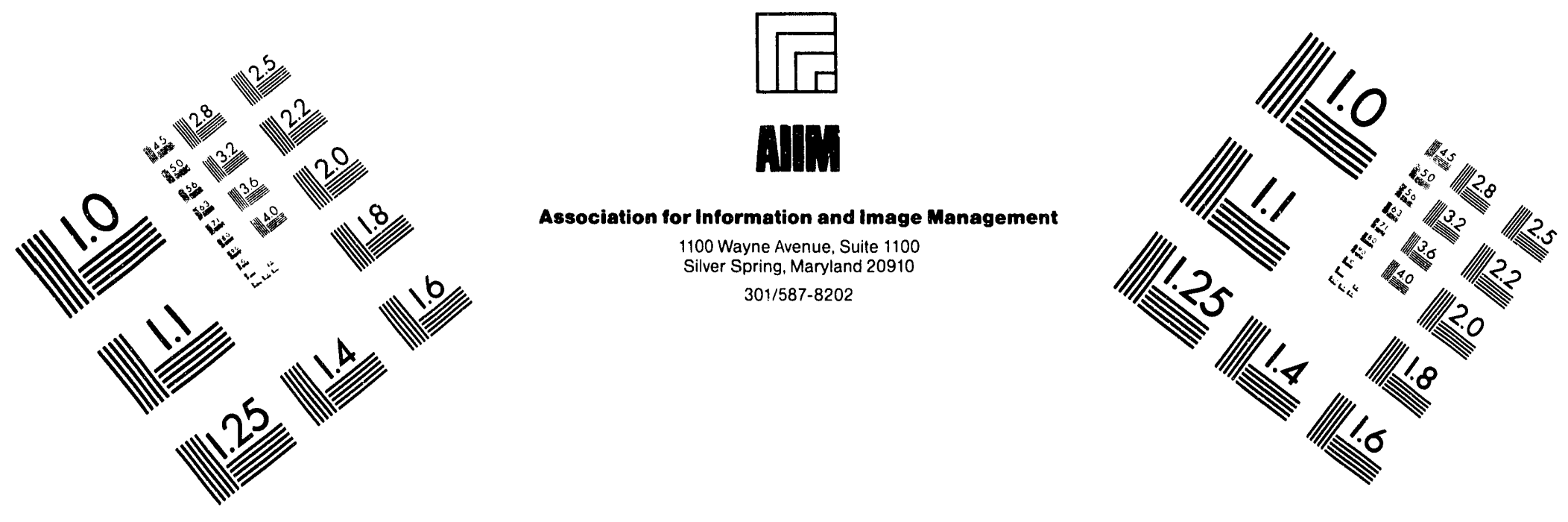

Centimeter

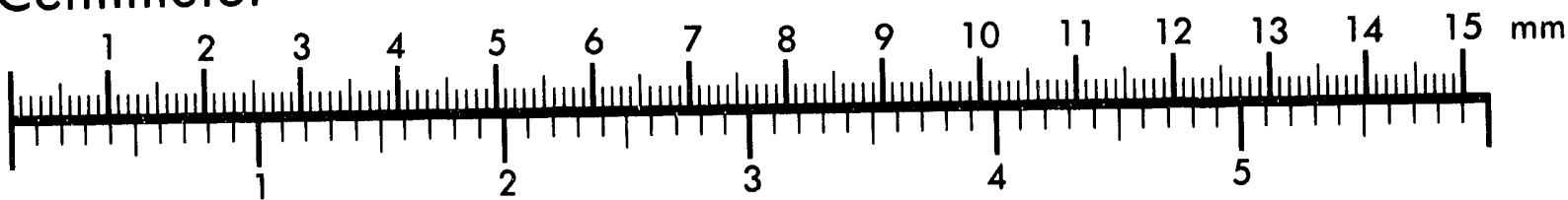
Inches
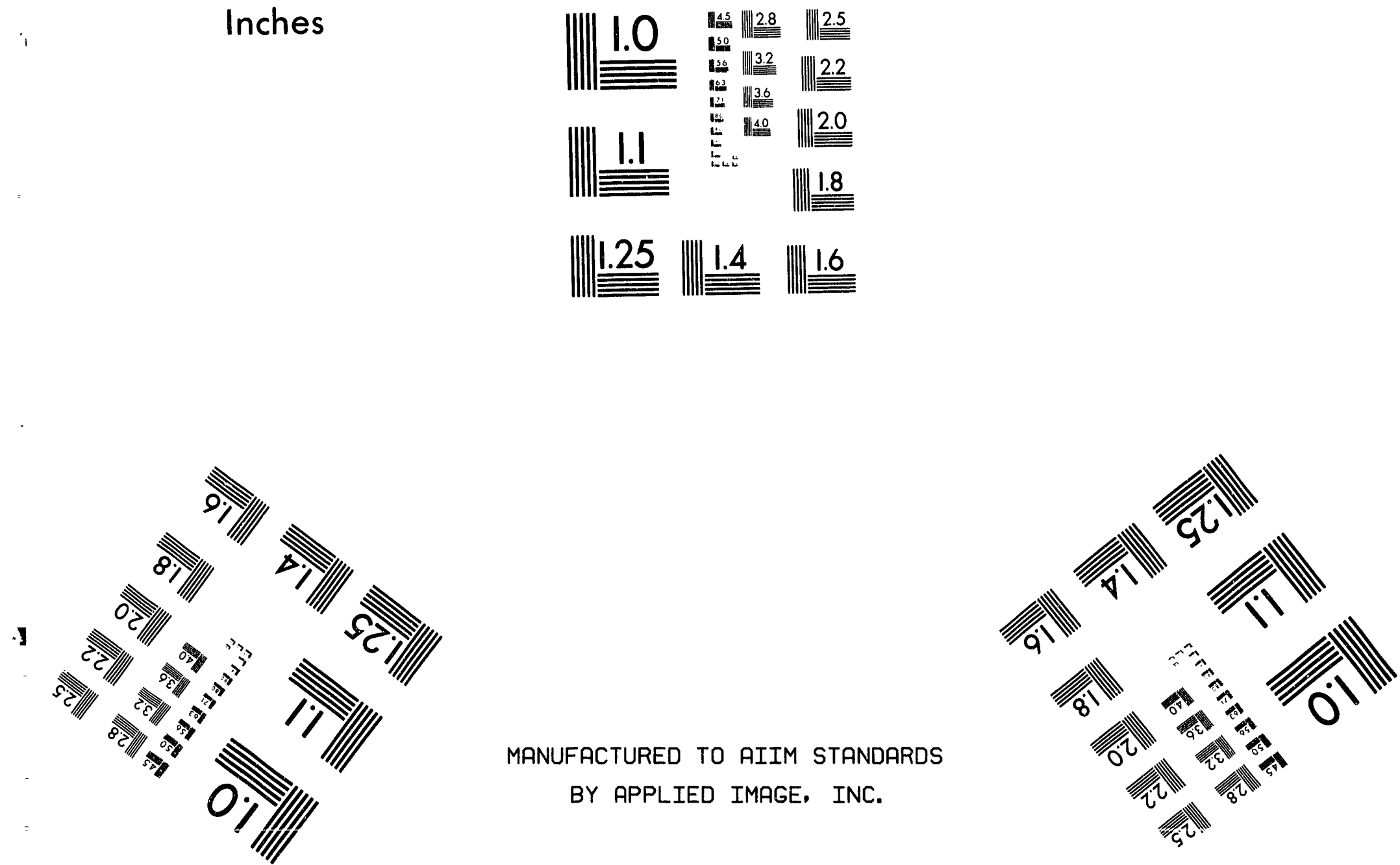

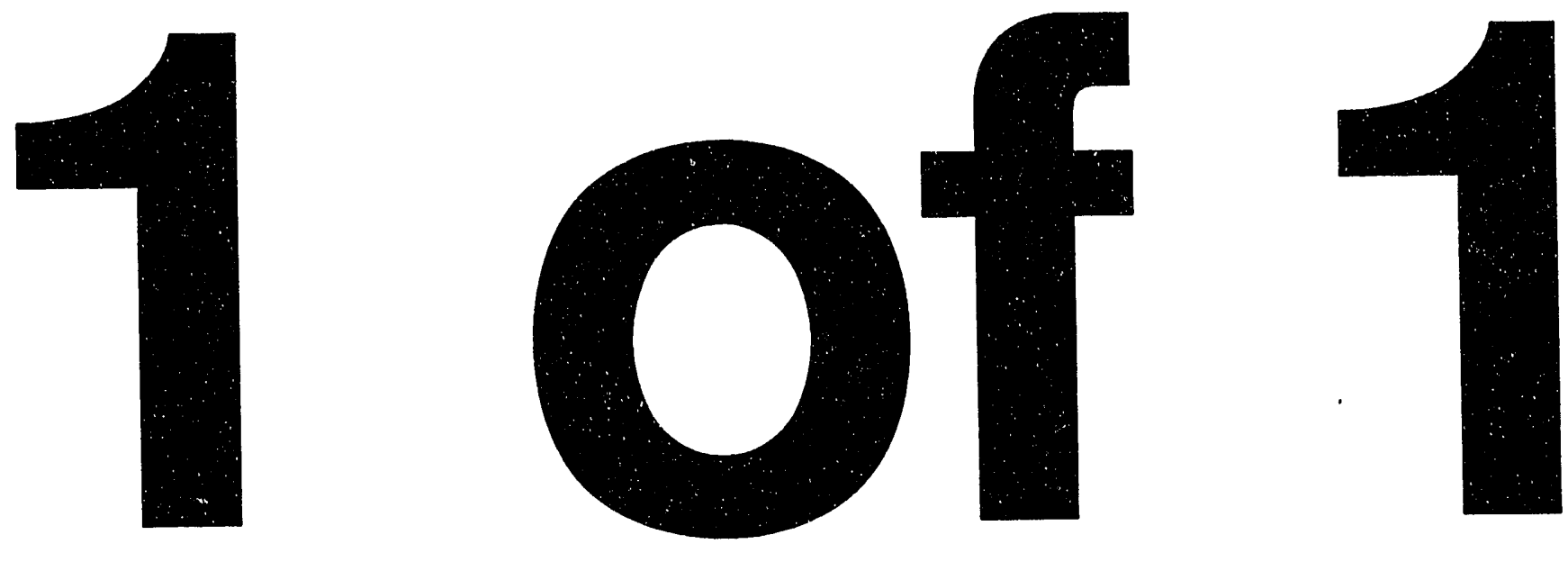


\title{
Dealing with Abort Kicker Prefire in the Superconducting Super Collider*
}

\author{
A. Drozhdin, I. Baishev, N. Mokhov, \\ B. Parker, R. Richardson, and J. Zhou \\ Superconducting Super Collider Laboratory ${ }^{\dagger}$ \\ 2550 Beckleymeade Avenue \\ Dallas, TX 75237
}

May 1993

\section{MithiER}

* To be presented at the 1993 IEEE Particle Accelerator Conference on May 17-20, Washington, D.C.

† Operated by the Universities Research Association, Inc., for the U.S. Department of Energy under Contract No. DE-AC35-89ER40486. 


\title{
Dealing With Abort Kicker Prefire in the Superconducting Super Collider
}

\author{
A.I.Drozhdin, I.S.Baishev, N.V.Mokhov, B.Parker, R.D.Richardson, and J.Zhou \\ Superconducting Super Collider Laboratory* \\ 2550 Beckleymeade Ave., Dallas, TX 75237 USA
}

\section{Abstract}

The Superconducting Super Collider uses a singleturn extraction abort system to divert the circulating beam to a massive graphite absorber at normal termination of the operating cycle or in case of any of a number of predefined fault modes. The Collider rings must be designed to be tolerant to abort extraction kicker prefires and misfires because of the large circulating beam energy. We have studied the consequences of beam loss in the accelerator due to such prefires and misfires in terms of material heating and radiation generation using full scale machine simulations and Monte-Carlo energy deposition calculations. Some results from these calculations as well as possible protective measures for minimizing the damaging effects of kicker prefire and misfire are discussed in this paper.

\section{INTRODUCTION}

The Superconducting Super Collider beam[1,2] contains approximately $420 \mathrm{MJ}$ of circulating beam energy per ring at the operating design point, proton momentum equal to $20 \mathrm{TeV} / \mathrm{c}$ and a circulating current of $70 \mathrm{~mA}$. This amount of circulating beam energy is equivalent to about $100 \mathrm{~kg}$ of high explosives and must be dealt with by a reliable abort system.

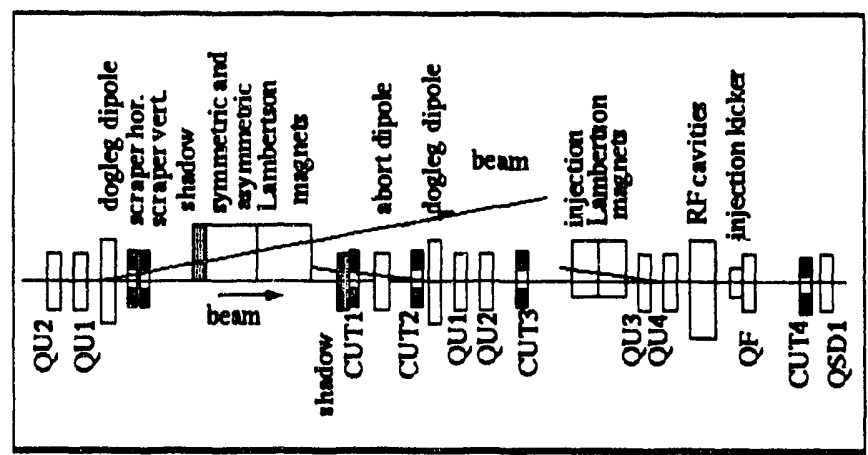

Figure 1. Collimators Locations in the West Utility

The abort system consists of 24 pulsed kicker magnets which direct the beam through the field free region of a series of Lambertson magnets on to a massive graphite absorber $[3,4,5]$. The abort kickers have a risetime of about $3 \mu \mathrm{s}$. Normally this system is triggered during the $4 \mu \mathrm{s}$ abort gap in the circulating beam and takes $290 \mu \mathrm{s}$ to extract

"Operated by the Universities Research Association, Inc., for the U.S. Department of Energy under Contract No. DE-AC3589ER40486.

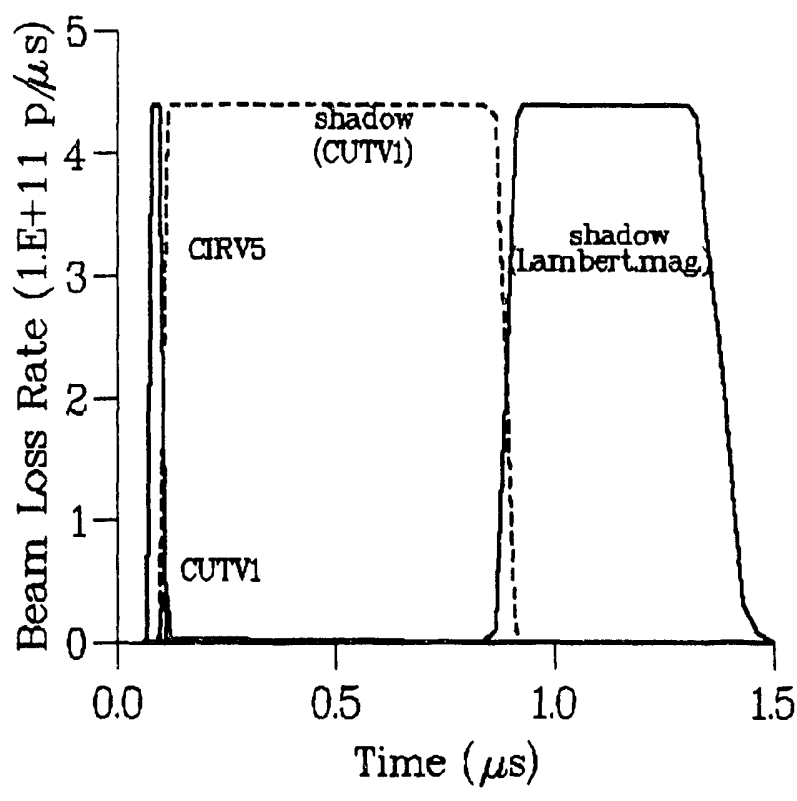

Figure 2. Beam Loss During the $3 \mu$ s Kicker Rise Time

beam from the full $87 \mathrm{~km}$ circumference of the Collider. If one or more kicker module either prefires or misfires, some fraction of the beam may not reach the absorber. The consequences of such a beam loss on accelerator components are discussed in the next section. In this paper particle tracing is done with STRUCT program[6]. Beam loss induced cascades and corresponding temperature rise is simulated with MARS12 code[7].

\section{ABORT PREFIRE PROBLEM}

An abort kicker prefire causes large amplitude coherent betatron oscillation of the beam and results in halo particles being intercepted by the collimators positioned around the ring. These particles can induce overheating of the collimator jaws up to hundreds of degrees. The most severe situation takes place at $20 \mathrm{TeV} / \mathrm{c}$ before or during collisions.

Simulations of this process have been done for the following assumptions. We assumed that the circulating beam is cleaned to the $10 \sigma$ level by a scraper which leaves $99 \%$ of the circulating beam inside of $4 \sigma$ and $1 \%$ of the beam between 4 and $10 \sigma$. Collimators are located in West Utility, as shown in Figure 1 and in the Interaction Region (IR) of the Collider (not shown) to protect low-beta quadrupoles against irradiation. For our initial simulations we assumed 
that these collimators are placed $4 \sigma$ inside the physical aperture of Collider. With an admittance of machine of $729 \mathrm{~mm}$.mrad or $2^{-} \tau$ of the circulating beam at top energy, the collimators were therefore positioned at $23 \sigma$ with respect to the Collider closed orbit.

For the worst case, when abort kicker prefire takes place just after the longitudinal abort gap passes, one needs to wait one full turn to resynchronize with the abort gap in order to cleanly remove beam from the Collider. For this case the overheating of IR collimator CIR5 considerably exceeds the meiting point of iron. In order to avoid overheating this collimator one could arrange to immediatly fire the next 23 kickers; however, according to our simulations one would have to limit the interval of time between the prefire and the start of the rest of the kickers to be less than about $5 \mu \mathrm{s}$. Unfortunately the full abort kicker pulse is unlikely to be contained within the abort gap and one has an unsynchronized abort. Results of a simulation of beam loss around the Collider during the $3 \mu$ s kicker rise time are presented in Figure 2. At low kicker field levels, halo particles are intercepted by a collimator in the IR and by the first collimator in West Utility. The temperature rise of these collimators are $400^{\circ} \mathrm{C}$ and $40^{\circ} \mathrm{C}$ respectively

At the level of about $10 \%$ of full kicker strength the deflected beam is intercepted by the first collimator in the West Utility. We must protect this collimator by a graphite shadow and temperature rise in shadow is $250^{\circ} \mathrm{C}$. At the level of about $40 \%$ of kicker strength the beam is intercepted by the graphite shadow of Lambertson magnet[8] and the shadow overheating is a tolerable $800^{\circ} \mathrm{C}$.

\section{PREFIRE PROTECTIVE MEASURES}

There are two ways we have investigated to avoid overheating of collimators and shadows:

- decreasing of the abort kicker rise time from $3 \mu \mathrm{s}$ to $1 \mu \mathrm{s}$ and

- compensating a prefired kicker by another kicker with opposite magnetic field (antikicker).

Decreasing the abort kicker rise time yields a three fold decrease in heating. For sufficiently short antikicker delay the full beam abort can be delayed until synchronization with the abort gap and thereby eliminating beam loss during the kicker risetime.

Recent simulations[9] suggest that the dynamic aperture of Collider at the top energy is around $12 \sigma$ and the lifetirne of the particles with large betatron amplitudes, from 12 to $20 \sigma$, varies from 50 to 2 turns. The lifetime is less than one turn for amplitudes greater than $20 \sigma$. For this case collimator jaws would have to be installed between $16-20 \sigma$ from the circulating beam axis to protect superconducting magnets irradiation and the collimator jaws would then intercept a more dense part of the circulating beam. This closer position would lead to an additional overheating about 20 times greater than for the $23 \sigma$ positions. The overheating of the collimator CIRV5 jaw during an unsynchronized abort increases to an inadmissible $900^{\circ} \mathrm{C}$. The first method of overheating reduction is ineffective in this case and only via an antikicker is it possible to eliminate the danger of collimator and shadow; damage.

The collimator jaw overheating is also strongly dependent 'ipon the delay between prefire and start of antikicker. Th. sulting kick and beam loss versus um: for different delas $(1.2 \mu \mathrm{s}$ and $1.65 \mu \mathrm{s})$ are presented in Figure 3,4. At $1.8 \mu$ s delay the result kick exceeds $75 \%$ of one kicker strength and collimator CIRV5 overheating exceeds melting point. Collimator jaws overheating versus antikicker delay is shown in Figure 5. An acceptable level of temperature rise of about $300^{\circ} \mathrm{C}$ is exceeded at $1.5 \mu$ s delay between prefire of abort kicker and start of antikicker. Providing a short $(<1.5 \mu \mathrm{s})$ delay is an important antikicker design requirement.

\section{CONCLUSIONS}

Our simulations show that for large $(>20 \sigma)$ Collider collimators settings an unsynchronized abort is allowed if graphite shadows are used upstream of the first abort Lambertson magnet and at a few critical collimator locations. For smaller collimator settings (between $14 \sigma$ and $20 \sigma$ ) an antikicker with less than $1.5 \mu \mathrm{s}$ delay appears to be needed to limit Collider equipment overheating to tolerable levels; however, further study is required in order to understand multi-kicker prefire and other failure scenarios.

\section{REFERENCES}

[1] Site-Specific Conceptual Design of the Superconducting Super Collider, SSCLab, July 1990.

[2] Collider Accelerator Arc Section, Element Specification (Level 3B), SSCL Document Control \# E10-000027, August 1992.

[3] Collider Accelerator Utility Section, Element Specification (Level 3B), SSCL Document Control \# E10000073 , March 1993.

[4] "Collider Preliminary Design Requirements Review (PDRR): Copy of Presented Transparencies," Available SSCL Library, January 1993.

[5] "Collider Abort Subsystem Conceptual Scheme and Optics: Copy of Transparencies", Brett Parker, Available SSCL Library, May, 1993.

[6] I.S. Baishev, A.I. Drozhdin, and N.V. Mokhov, SSCL306, Dallas (1990).

[7] N.V. Mokhov, The MARS12 Code System, Proc. of SARE Workshop, Santa Fe, 1993, See also N.V. Mokhov, Fermilab FN-509, 1989.

[8] N.V. Mokhov, Collider Utility Section PDRR, SSCL, Jan. 1993.

[9] Y. Cai, Private Communication, Available SSCL Library, April 1993. 

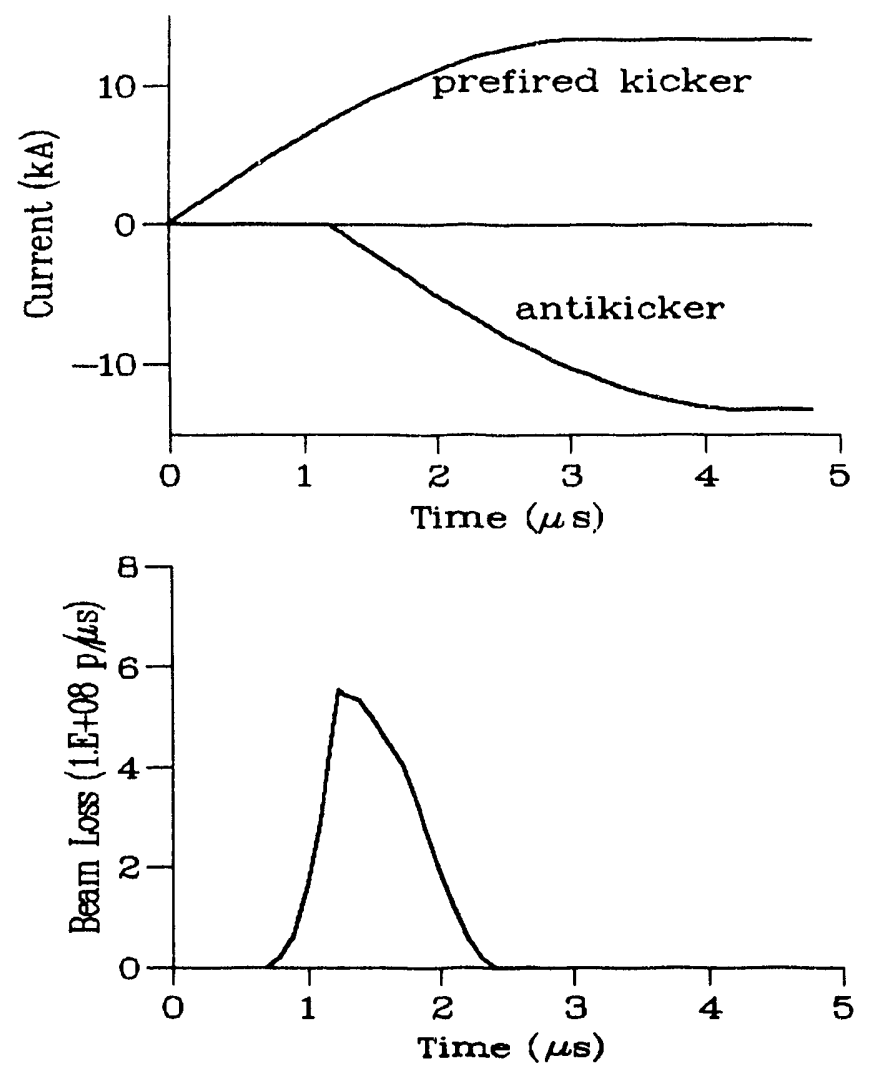

Figure 3. Kicker/Antikicker Pulse Shape (top) and Beam Loss Versus Time (bottom) for $1.2 \mu \mathrm{s}$ Delay
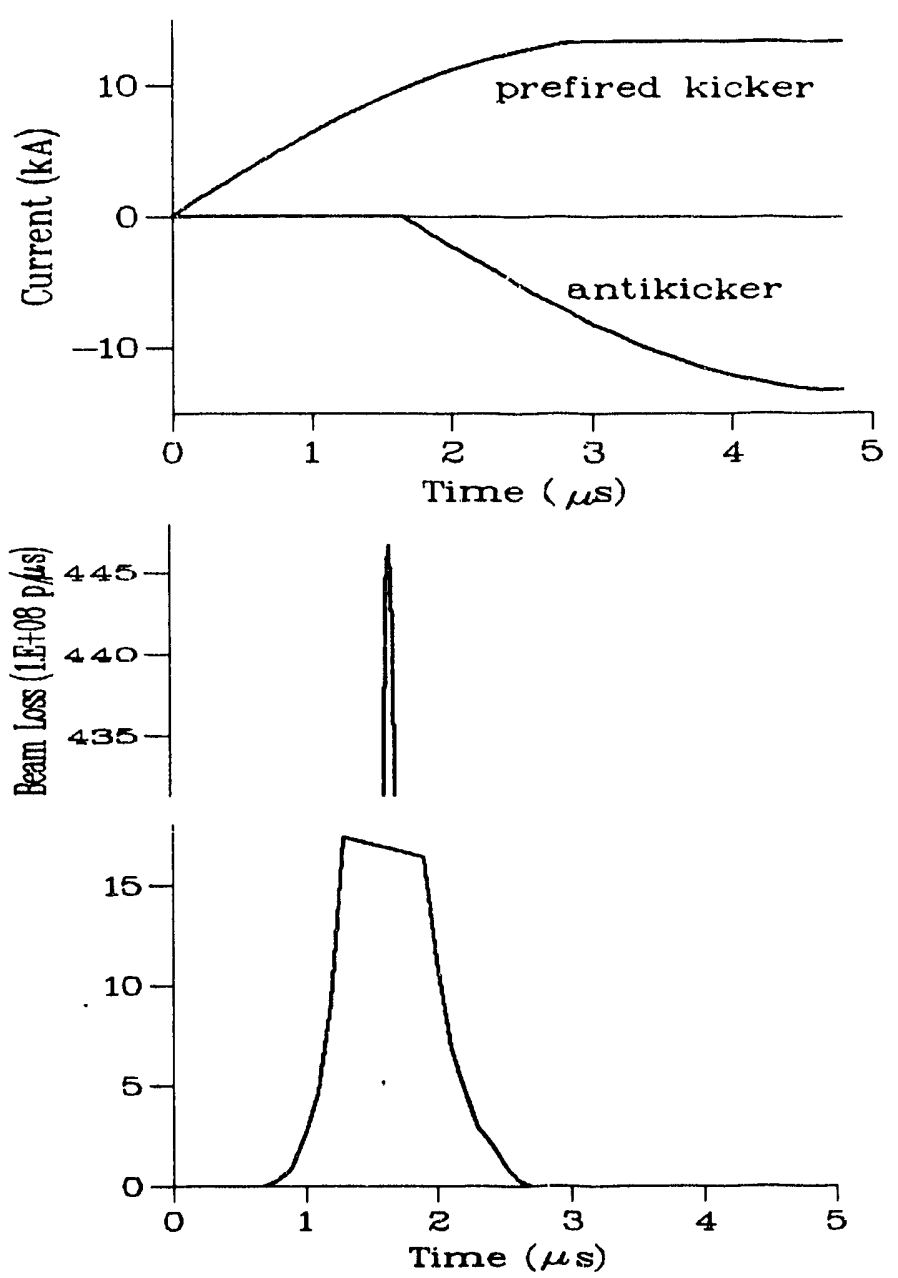

Figure 4. Kicker/Antikicker Pulse Shape (top) and Beam Loss Versus Time (bottom) for $1.65 \mu$ s Delay

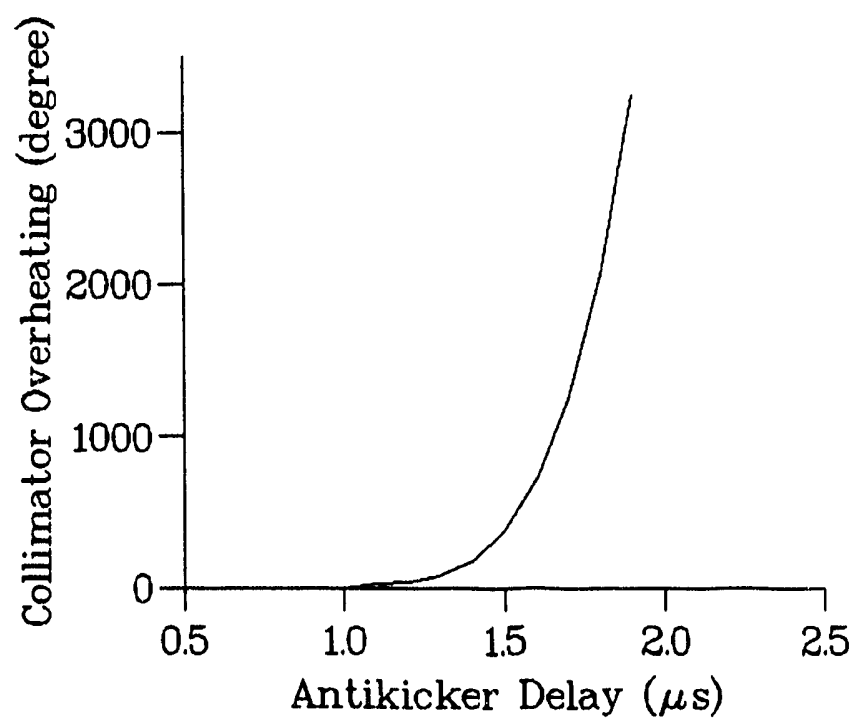

Figure 5. Collimator Jaws Overheating Versus Antikicker Delay 

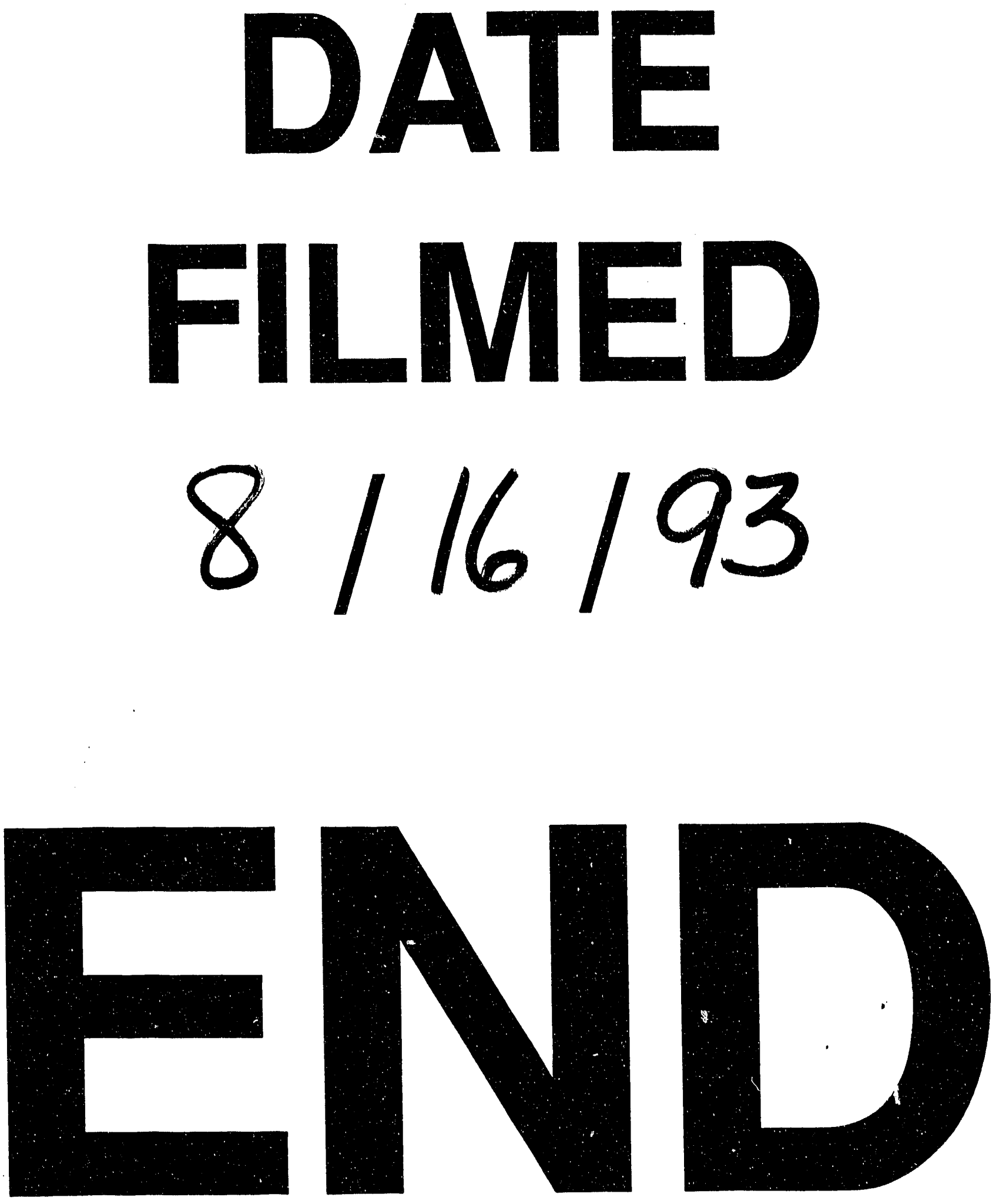
